\title{
El Puerto de Santa María ante 1898
}

\author{
M. ${ }^{a}$ del Carmen Borrego Plá \\ Universidad Hispalense, Sevilla
}

\begin{abstract}
Tal y como su título indica, el presente estudio trata sobre el impacto del 98 en El Puerto de Santa María, ciudad localizada en la bahía gaditana, auténtica cabeza de puente con las Antillas. Temática ésta de la que hasta ahora muy poco se conocía, se ha fundamentado en diversas fuentes locales, con el objetivo de estudiar dicho impacto de la manera más amplia posible: estructura socioeconómica de la zona, respuesta de la misma al conflicto bélico, opinión que de él se tenía y cotidianidad del momento. Finaliza con el análisis de la filosofía regeneracionista y de progreso que llegaría a toda España y por tanto también a El Puerto. Pero que en éste último caso y debido a las especiales características del mismo, daría lugar a una original clave de futuro que aún hoy día está vigente.
\end{abstract}

\section{La coyuntura de una crisis}

En los estertores del siglo XIX toda la bahía gaditana - y por ende la localidad portuense- hacía ya tiempo que había dejado de ser aquella zona relativamente próspera y feliz que se reflejara años atrás en algunas crónicas del momento. Después de una dificilísima andadura histórica, su inestable conformación socioeconómica aparecía ahora víctima de terribles hachazos. En primer lugar, la explosiva situación de la tierra, concentrada en muy pocas manos gracias a las respectivas compras provenientes, según el caso, de la desamortización eclesiástica o de las grandes desvinculaciones patrimoniales efectuadas por la nobleza. Sin apenas industria, su principal cultivo radicaba en el cereal y sobre todo en la vid, aunque esta última, a su vez, estaba siendo víctima de una terrible plaga de filoxera que amenazaba su propia existencia. Todo ello inserto en un cuadro meteorológico muy cíclico, con períodos alternativos de sequías e inundaciones - la última en 1895-, que habían dado al traste con gran parte de las cosechas. ${ }^{1}$

Y como segundo problema a destacar, aunque de importancia similar al primero, la negra perspectiva en que se encontraba la pesca, característica fuente de riqueza portuense desde el inicio de los tiempos y que se debatía ante deficiencias estructurales de todo tipo. Hacía falta ampliar su

1 Borrego Plá, Carmen: "El comercio del vino y El Puerto de Santa María en la crisis del noventa y ocho". Andalucía y América en el siglo XIX. Actas de las V Jornadas de Andalucía y América. Sevilla, 1986, vol. I, págs. 455-479. 
puerto, dragar el citado Guadalete, renovar su flota pesquera por entonces en competencia frontal con los barcos de vapor, estudiar la conveniencia de determinadas artes — sobre todo las desarrolladas por los "bous"-, para tratar de evitar la esquilmación de las especies...2

Como resultado de lo expuesto, una población laboral rozando mayoritariamente la penuria en unos momentos muy proclives a la escasez y carestía de abastecimientos. Un ejemplo de lo dicho, el que en 1897 un kilogramo de vacuno o carnero costase 1,60 pesetas, el de cerdo 2 y el de ternera 4 pesetas respectivamente. Por su parte, el kilogramo de "pan de primera" aparecía a 58 céntimos y a 50 y 45 los de calidades inferiores. A destacar, el que no hubiese harineras en Andalucía, debiendo efectuarse el proceso de transformación en las catalanas, con el consiguiente encarecimiento que ello suponía en los costes de la mencionada panificación. ${ }^{3}$

No es de extrañar pues que todo este segmento laboral conformase la principal "clientela política" del partido anarquista, de gran implantación en toda la zona. Gente bronca, dura y difícil que tan extraordinariamente retrataran algunos autores como Azorín o Blasco Ibáñez ${ }^{4}$ y cuyas reivindicaciones, expuestas de forma muy violenta, serían una gravísima nota para desestabilizar un panorama de por sí tan sombrío. ${ }^{5}$ Fenómeno todo el tan interesante como poco conocido y que estaría siendo objeto actualmente de diversos estudios aún en fase de elaboración. El colofón a todo lo expuesto, vendría dado por una despoblación cada vez mayor en el área local portuense, que si en 1887 contaba con 20.000 personas como población de derecho, diez años después había descendido a 18.500. La propia prensa del momento llegaría a denunciar: "Unos, engolfados en las cues-

2 La curiosa denominación de "bou" para muchos autores tendría un origen levantino, pudiendo traducirse por "buey", dado que dichas embarcaciones faenaban en parejas, recordando la yunta de bueyes. Para todo lo referente a la mencionada actividad pesquera resulta útil el trabajo de Carmen Borrego Plá: "Prensa y pesca portuense en los inicios del siglo XX", Andalucía, América y el Mar. Actas de las IX Jornadas de Andalucía y América, Sevilla, 1991, págs. 91-121; así como el de José Ferrer Andrade: "La motorización de la flota pesquera portuense", Revista de Historia del Puerto, 1993, n. ${ }^{\circ} 11$, págs. 53-57.

3 Borrego: "Prensa y Pesca...", pág. 99.

4 Azorín: "Andalucía Trágica". Obras Completas. Madrid, 1947, vol. III, págs. 205-231. Blasco Ibáñez, Vicente: La Bodega. Sevilla, 1989.

5 Sobre las raíces y comportamiento del anarquismo en la provincia de Cádiz quedan aún muchos interrogantes por estudiar, pero como orientación y ayuda, dada la numerosa bibliografía que recogen, pueden citarse entre otros, los trabajos de Iglesias Rodríguez, Juan José: El Puerto de Santa María. Cádiz, 1985; Cabral Chamorro, Antonio: Agronomía, agrónomos y fomento de la agricultura en Cádiz. 1750-2855. Cádiz-Jerez, 1995; Mateo y Avilés, Elías de: La emigración andaluza a América (1850-1936). Málaga,1993; así como los de Borrego Plá: "Prensa y Pesca...” y "El comercio del vino...", págs. 455-478. 
tiones políticas, otros, entregados a los placeres, olvidan que se precisa una solución". ${ }^{6}$

Pero por si todo ello no fuera suficiente, en el horizonte peninsular permanecían aún los negros nubarrones de una guerra allende el Atlántico que parecía no tener fin. La isla de Cuba, el último eslabón colonial, andaba revuelto desde hacía tiempo. ${ }^{7}$ Desde 1895 en que se diera el famoso Grito de Baire, El Puerto de Santa María había visto marchar a muchos de sus hijos rumbo a Cádiz, donde, en medio de alegres despedidas, las tropas desfilaban eufóricas, pensando en la victoria, después de haberla celebrado prematuramente en sugestivos banquetes con asistencia de las principales autoridades provinciales y locales. Los gaditanos, orgullosos, las veían partir, regalándoles recuerdos, como pañuelos o petacas... ${ }^{8}$

Pero el tiempo pasaba, el desarrollo bélico no tomaba el rumbo previsto y muy pronto la euforia se trocó en descontento. La posibilidad de un desastre iba poco a poco calando en la clase política española y cuando en 1897 el conservador Cánovas moría a manos de un anarquista, el nuevo gobierno liberal, con su presidente Sagasta a la cabeza, decidió efectuar un giro en las relaciones hispanocubanas. La confrontación bélica, hasta aquellos momentos en manos del general Weyler, fue cambiada por una salida política, basada en una amplia autonomía con un parlamento y administración propias. ${ }^{9}$

Para entonces —inicios del fatídico 1898 - , nuestra localidad portuense, aunque sin perder nunca de vista los sucesos isleños, vivía con intensidad la realidad cotidiana. En este sentido, por ejemplo, su consistorio se encontraba inmerso en un desesperado intento por potenciar la ciudad. De entre las medidas a tomar, la insistente solicitud al Ministerio de Fomento para que ampliase el sistema portuario y la red viaria, dada la extraordinaria repercusión que todo ello tendría para la zona en cuestión. Incluso la citada institución municipal, ante la proximidad de los carnavales, iniciaba una mejora en el adecentamiento de la ciudad, fijando su atenro de 1895 .

6 Borrego: "Prensa y Pesca...", pág. 99. "Cifras que hablan". La Revista Portuense, 6 de ene-

7 Navarro García, Luis: La Independencia de Cuba. Madrid, 1991, págs. 349-381.

8 Baraja Montaña, Manuel: La Guerra de Independencia Cubana a través del Diario de Cádiz. 1895-1898. Cádiz, 1979, pág. 47.

9 Navarro: La Independencia..., págs. 361-367. Como obra de conjunto respecto a lo que estos momentos históricos significaron para España, puede consultarse La Nación Soñada: Cuba, Puerto Rico y Filipinas ante el 98. Edit. Consuelo Naranjo, Miguel Angel Puig-Samper y Luis Miguel García Mora. Madrid, 1996. 
ción especialmente en la Plaza de Isaac Peral y alrededores, "para que desaparezcan los rincones perjudiciales para el boato público". ${ }^{10}$

Aunque asunto igualmente importante sería la subasta pública por 4.900 pesetas del pósito municipal, edificio que otrora fuese de don Gabriel Selma y que se encontraba situado en el número 2 de la calle Ejido, lo que provocaría más de un problema en el abastecimiento de los batallones que marchaban a Cuba, según posteriormente veremos. ${ }^{11}$

Por último habría que destacar el intento de los munícipes por tratar de solventar los ya endémicos conflictos derivados de una difícil sanidad pública. Porque El Puerto, entre el más que cuestionable alcantarillado, la adversa climatología ya expuesta, la costosa llegada de agua potable desde el Manantial de La Piedad y la proximidad del Penal, siempre había estado amenazado de fiebres y epidemias. Por ello este año de 1898 las arcas municipales libraron 144 pesetas para vacunar contra la difteria a todos los mendigos e indigentes - "vagamundos"- que pululaban por la ciudad. Ya existía demasiado peligro de contagiarse con la fiebre amarilla que traían los repatriados cubanos, para que la situación se complicase con otro tipo de enfermedades. ${ }^{12}$

De alguna u otra forma, Cuba pues siempre presente, aunque observada políticamente desde la suspicacia. Porque al contrario de lo que ocurría en otros lugares, como por ejemplo Sevilla, más esperanzada con las medidas autonomistas, ${ }^{13}$ en El Puerto la opinión mas generalizada era la de que dicha autonomía no respondía a ningún tipo de panacea y que los Estados Unidos no iban a abandonar sus veladas ansias expansionistas.

Al menos esto era lo que recogían los dos periódicos del momento, ambos de carácter conservador, aunque con determinados matices diferenciadores. Ellos fueron los únicos medios de información y de expresión populares, ya que los correspondientes a otros sectores mas izquierdistas - por ejemplo El Sudor del Obrero, de ideología anarquista- no aparecerían hasta pocos años mas tarde. Siguiendo pues estos parámetros expuestos, los escasos números existentes de La Región Andaluza, semanario conservador de corte muy extremista, aunque en sus editoriales se autodefiniera como "conservador liberal" o "conservador a la moderna",

10 Archivo Municipal de El Puerto de Santa María (AMPSM), acta de cabildo, 21 de enero de 1898. fol.24.

11 Ibídem, 4 de febrero de 1898, fol. 24.

12 Ibídem, fol. 20.

13 Sevilla Soler, Rosario: La Guerra de Cuba y la memoria colectiva. La crisis del 98 en la prensa sevillana. Sevilla, 1996, pág. 136. 
solicitaron machaconamente la dimisión del gobierno liberal. Como causa, la inoportuna destitución del general Weyler y la "vergüenza que había supuesto la autonomía para la integridad y el honor de España". A veces incluso el colofón poético no solía faltar: "!Frutos de la autonomía,/ venid a inspirar mi pluma/ y haced subir cual la espuma/ de la ciega idolatría;/ ...entre sarcasmos la patria/ de Bailén y de Lepanto/... venid por esos caminos/ que alumbró nuestra Nación,/ para otorgar el perdón/ de cobardes y asesinos! $/{ }^{\prime 14}$

A la misma conclusión - aunque con expresiones menos hirientesllegaría La Revista Portuense, diario igualmente conservador pero de sesgo bastante mas moderado, muy inspirado por la encíclica Rerum Novarum de León XIII. A comienzos del mes de enero dicho periódico reproducía un sustancioso artículo del también conservador gaditano don Emilio Castelar, en el que la citada autonomía era considerada como "una mala cosa". Siempre según su opinión, los autonomistas, una vez conseguido el poder político, al igual que había ocurrido con los revolucionarios franceses, se habrían enquistado en el mismo, no consiguiendo su intolerancia atraer hacia sí a un mayor número de ciudadanos, fundamentalmente "los conservadores, que son los que tienen el poder y la riqueza".

No obstante, continuaba, su laxitud era manifiesta con la prensa, ya que al no aplicársele la censura propia de un estado de guerra, se propiciaba "que pudiera decir lo que se le antojase de cada jefe, de cada grupo en armas... Cosa que solo resultaba aconsejable en épocas de absoluta tranquilidad". En aquellos difíciles días, el gobierno autonomista de la Isla —proseguía—, estaba en manos de reformistas - Ministerio de Comercio, radicales históricos — Hacienda y Presidencia del Consejo—, así como de radicales intransigentes — Justicia e Instrucción-, por lo que se hacía necesaria una negociación. "No teman los nuevos ministros que les llamen "pasteleros", con tal que su pastel, bien condimentado, procure a Cuba paz y libertad". ${ }^{15}$

Y para incidir aún más en la ineficacia autonómica, La Revista en cuestión reproducía igualmente días mas tarde la totalidad del Manifiesto Cubano dado el 30 de octubre del año anterior en La Yaya (Camagüey). En el mismo, los independentistas reunidos en Cámara Constituyente para elegir un gobierno provisional, al grito de "Libertad o Muerte", habían pro-

14 "Aclaración Necesaria" y "Frutos de la Autonomía". La Región Andaluza, 19 y 11 de ene-

15 "El Gobierno Cubano". La Revista, 2 de febrero de 1898. 
clamado su derecho irrenunciable a la independencia. Porque para ellos la autonomía resultaba el recurso extremo de España,

"que nos remite leyes cuando no puede enviarnos soldados... Mientras Cuba, arruinada por una deuda enorme, con la perspectiva de una costosísima ocupación militar, entregada a una administración deshonrada y deshonrosa, oprimida por los aranceles, vive entre la desconfianza, el celo y la miseria". ${ }^{16}$

De lejos, como gendarme vigilante, el coloso norteamericano, con un presidente republicano, McKinley, quién no ocultaba su deseo más o menos velado de que la isla caribeña entrase de cualquier forma en la órbita de la nación que él presidía. Incluso - a través de una asociación bancaria - había llegado a ofrecer secretamente a España la compra de su independencia por 150 millones de dólares, además de otro millón para los políticos que gestionasen dicha cesión. La estratagema recordaba mucho la utilizada tiempo atrás con México, el cual, por 15 millones de pesos, le había vendido Texas, Nuevo México y la Alta California. ${ }^{17}$ Pero la reacción del gobierno español fue muy distinta al mexicano. Su negativa a semejante maniobra fue terminante, quedando a la espera de la impredecible respuesta norteamericana.

Por su parte, en el pueblo y aun sin llegar a conocer estos extremos, la alarma iba creciendo; y como muestra paradigmática de todo ello, la prensa portuense reproducía la entrevista efectuada al director del Mundo Naval por el corresponsal del New York Herald, Mr. Ambrey Stanhope. En la misma éste último "espontáneamente" explicaba las amistosas relaciones de Estados Unidos con España, citando como ejemplo un futuro e importante tratado comercial, que con toda seguridad iba a ser firmado entre ambas naciones. Pensaba que, con ello, se podía de alguna forma suavizar las pretensiones estadounidenses, de que el gobierno español abonase las pérdidas que habían sufrido los intereses norteamericanos en la Isla con motivo de la insurrección, y que ascendían a varios millones de duros.

Asimismo hacía especial mención a las ansias de paz de sus compatriotas y al respeto que todos ellos tenían por la extraordinaria y experimentada artillería española, aclarando que la futura visita del acorazado "Maine" era mera cortesía. Terminaba con las siguientes palabras: "esté usted seguro que con su presencia no se producirán conflictos, aún cuando

16 "La Autonomía. Manifiesto Cubano". Ibídem, 10 de febrero de 1898.

17 Navarro: La Independencia..., pág. 370. Morales Padrón, Francisco: Historia de unas Relaciones Difíciles (EEUU-América Española). Sevilla, 1987, págs. 82-83. 
ocurra cualquier suceso desagradable". ${ }^{18}$ Ante esto, los portuenses se preguntaban:

“ ¿No encuentran modo de demostrar su cordialidad los Estados Unidos que enviando buques a Cuba?. ¿Porqué no la demuestran evitando la protección que se da por los americanos yankees a la insurrección?. ¿Es un alarde de fuerza o un apresto para la guerra?". ${ }^{19}$

\section{La consumación del Desastre}

La tensión alcanzaba su cenit cuando a mediados de febrero estallaba el "Maine", convulsionando a toda la Península. La desorientación española al respecto resultaba evidente. En El Puerto era tiempo de carnaval y curiosamente su alcalde recibía la siguiente orden desde el gobierno civil de Cádiz:

"Deseando evitar que con pretexto de disfraces o mascaradas pueda lastimarse la susceptibilidad de las naciones extranjeras, o de personalidades y clases respetables, con alusiones de dudosa cultura, me dirijo a usted, manifestándole que no debe autorizarse nada que tienda al indicado fin". ${ }^{20}$

En realidad tamaña prevención estaba justificada por las letras de los carnavales de años anteriores, en los que Cuba siempre había estado presente de mil formas distintas: ironía, dolor, ternura, nostalgia, brabuconería... ${ }^{21}$ Ya en 1896 el coro de "Las Cantineras de Cuba" —nombre mas que indicativo- había profetizado:

"Lo que más nos entristece/ y lo que mas deploramos/ es tener que pelear/ con nuestros propios hermanos/. Que la sangre derramada/ caiga sobre los nacidos/ de esa avarienta nación/ llamada Estados Unidos/". ${ }^{22}$

Sin embargo, a pesar de todas las prohibiciones y censuras, en este año de 1898 las coplas, versos y letrillas continuarían haciendo referencia

18 "Declaraciones Interesantes". La Revista, 1 de febrero de 1898.

19 "Las Visitas de los yankees". Ibídem, 11 de febrero de 1898.

20 Muy interesante, dado lo poco que se conoce sobre el tema, es la obra de José Ignacio Buhigas y Tily, Santiago: Carnaval: un siglo de historia del Puerto (1836-1936). El Puerto de Santa María-Cádiz, 1983, pág. 153.

21 Ibídem, pags. 77-83.

22 Ibídem, pág. 79. 
al asunto isleño, aunque ahora las diatribas iban no sólo contra los yanquis, sino también contra la — a veces interesada — ineficacia de la administración española para buscar una solución. A este respecto el coro de "Los Aragoneses" llegaba a cantar:

“¿Qué es lo que en Cuba sucede/ nosotros nos preguntamos/ que la guerra tanto dura/ y tan poco adelantamos?/... Y mientras muere el soldado/ se gastan nuestros millones/ y vemos muy encumbrado/ al que no tenía calzones/".

Por su parte, el coro de "Los Excéntricos" ironizaba:

"Como señal de respeto/ y de cortesía/ mandan los yanquis a Cuba/ su acorazado mejor./ Seguramente no hay otro Gobierno en la Tierra/ que su amistad demuestre/ mandando barcos de guerra.../Voy a hacer con mis amigos/ lo que manda la etiqueta/ y cuando vaya a sus casas/ iré apuntando con escopeta/". ${ }^{23}$

Mientras tanto la situación se hacía cada vez más compleja, al aducir los Estados Unidos que la causa del desastre del "Maine" "era debida a un agente externo". Por su parte, España se reafirmaba en que el problema se había desatado dentro de la propia sala de máquinas del citado navío, lo cual no era de extrañar, dado que los destructores "Iowa" e "Indiana" habían sufrido accidentes similares en las Islas Tortugas. ${ }^{24}$

Eran días en los que nuestra prensa en cuestión se hacía eco de cómo los viajeros recién llegados de la Isla sentenciaban convencidos: "aquello se pierde". Para los mas radicales, la confrontación armada con la todopoderosa nación norteamericana parecía inevitable:

"Los que buscaban la paz de manera indecorosa se equivocaban, porque por ese camino se va a la pérdida de la perla de las Antillas... ¿Qué hemos adelantado con tanta blandura?. Va a caer en manos de la Unión el árbol regado con el oro y la sangre españoles... Hay que dejar a un lado temores femeninos impropios de nuestra historia. Mala es la guerra, pero peor la expoliación". ${ }^{25}$

Las críticas generalizadas ante "la desdichada autonomía" eran constantes por parte de todos, porque - en su opinión - había despertado las ansias expansionistas del vecino norteño. Y ello a pesar de que "estos autonomistas no van a tener ninguna ventaja... Los yankees consideran a Cuba

23 Ibídem, págs. 83 y 80.

24 "Ya es bastante". La Región, 23 de febrero de 1898.

25 "La paz a toda costa". Ibídem, 19 de marzo de 1898. 
un país conquistado". ${ }^{26}$ La coyuntura política del momento se hacía cada vez mas difícil y los ánimos continuaban caldeándose:

"No faltan por desgracia los pobres de espíritu que en su afán de sacarle punta a los cuernos de la luna, culpan a la prensa periódica de cuantas calamidades nos agobian y claman contra los que ellos llaman los abusos intolerables del noticismo a la moda... ¿Puede nadie que se precie de español y que de liberal blasone, pedir correctivo para nuestro periodismo, hoy mas que nada sensato y prudente?". ${ }^{27}$

España llegó incluso a pedir la mediación del papa León XIII, aunque el Vaticano únicamente se limitó a instar a la negociación entre ambas partes. Para entonces McKinley había conseguido ya que el Congreso le concediera libertad para actuar en dicho asunto. La contienda colonial se había convertido en internacional, declarándose la guerra el 24 de abril. ${ }^{28}$

La campaña, al igual que en el resto de España, comenzó a verse como un "Juicio de Dios" entre un mercader infame y un ejército lleno de historia y honor. ${ }^{29}$ La propia Revista Portuense sería proclive a relatos y composiciones épicas, algunas con títulos tan sugerentes como

"La Bandera y La Espada": "La verdad, a tiempo vienes,/ que mi pabellón glorioso/ por nadie jamás vencido/ hoy se mira escarnecido/ por un pueblo codicioso/ que juzga fácil victoria/ quitar a la hispana gente/ la perla mas reluciente/ de su diadema de gloria/". ${ }^{30}$

El Ayuntamiento, por su parte, emitía un bando, cuyo contenido debió ser similar al dictado por otros municipios, en el que se solicitaba el sacrificio económico del vecindario para ayudar a la Suscripción Nacional abierta en Madrid con motivo de la guerra. Porque como el Santo Padre había indicado: "todo se puede tolerar menos el deshonor". ${ }^{31}$

Aunque el principal problema radicaba en las posibles consecuencias del conflicto. La propia autoridad militar gaditana, temiendo un eventual ataque yanqui a toda la zona, dado su alto valor estratégico, militar y naval, tomaba las medidas oportunas. E inmediatamente El Puerto recibía la orden de establecer una fácil comunicación con el castillo de Santa Catalina, situa-

26 "Haciendo Historia", La Revista, 1 de marzo de 1898.

27 "Réplica a los Sensatos". Ibídem, 19 de marzo de 1898.

28 Baraja: La Guerra de Independencia..., págs.197-202. Navarro: La Independencia..., págs. 371-381.

29 Sevilla: La Guerra de Cuba y la memoria..., pág. 58.

30 "La Bandera y La Espada". La Revista, 23 de abril de 1898.

31 "Bando del Ayuntamiento". Ibídem, 23 de abril de 1898. 
do a sus afueras, bajo promesa gubernativa de que se mejorarían las instalaciones militares de éste último. Asimismo y por idéntico motivo, el citado consistorio se veía obligado a concentrar en el cuartel del Polvorista, a los pequeños destacamentos de la guardia civil ubicados hasta entonces en $\mathrm{La}$ Puntilla, El Salao, La Bermeja, La Victoria y Pescadería. ${ }^{32}$

Las razones de semejante "alerta" se justificaban ante las extraordinarias relaciones que mantenían los Estados Unidos con Gran Bretaña, la cual les podía llegar a prestar la cercana Gibraltar como base logística, "permitiendo al enemigo adquirir todo lo necesario de víveres y municiones...Por este motivo era justa la prevención de un ataque a esta plaza - Cádizdesde el momento en que se decidiera una escuadra yankee a venir a la Península". Con ello incluso se corría el peligro - finalizaban los estrategas gaditanos-, de que Inglaterra viera por fin colmada su antigua obsesión histórica: contemplar la "conquista" del puerto de Cádiz. ${ }^{33}$

En otro orden de cosas, se solicitaba igualmente información del grano y harina existente en El Puerto, con vistas a un eventual abastecimiento de la tropa. La respuesta, que no se haría esperar, recogía la inoperancia del pósito municipal - ya comentada - , pero proporcionaba la lista de aquellos vecinos - Sinforiano Molleda, Julián García, José de la Cuesta, Serafín Álvarez, Domingo Yato, Manuel Rosado, José Leonisio y José Velarde-, que disponían de cantidades suficientes para ser adquiridas en caso de necesidad, las cuales ascendían a 66.504 y 148.292 kilogramos de harina y trigo respectivamente. Ellos serían de los pocos portuenses que sacasen algún provecho de esta guerra ultramarina, dada la necesidad de avituallamiento que para la travesía oceánica presentaban los navíos atracados en el cercano puerto gaditano. Como también lo sería la Compañía Trasatlántica que — con sede en éste último—, poseía el monopolio de dicho transporte, percibiendo 32 pesos por soldado, "más de lo que pagaba un particular viajando en primera clase". ${ }^{34}$

32 AMPSM, legajo 1282, Guerra 1898, n. ${ }^{\circ}$ 5. Orden del gobernador de Cádiz al alcalde de El Puerto, Cádiz, 18 de abril de 1898 y el alcalde de El Puerto al gobernador de Cádiz, El Puerto, 31 de mayo de 1898.

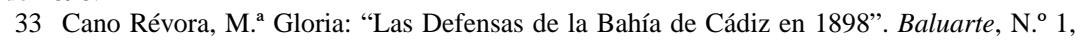
Cádiz, 1995, págs. 133-145.

34 AMPSM, legajo 1282, Guerra 1898, n. ${ }^{\circ}$ 5. Gobernador de Cádiz al alcalde de El Puerto, Cádiz, 11 de mayo de 1898 y certificación del administrador José Joaquín de Castro del trigo y harina existentes en los depósitos autorizados por la administración de consumo, El Puerto, 11 de mayo de 1898. AMPSM, legajo 409, Contribución Industrial 1895-1902. Hernández Sandoica, Elena y M. ${ }^{a}$ Fernanda Mancebo: "Higiene y sociedad en la guerra de Cuba (1895-1898). Notas sobre soldados

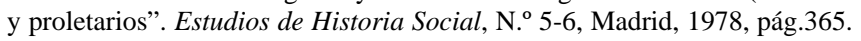


Mientras tanto, el gobierno acentuaba su presión sobre el alistamiento de la tropa no profesional, dada la negativa marcha de la contienda. Para entonces los triunfales embarques se habían trocado ya en despedidas amargas. No había ni banquetes ni desfiles; sólo una comida de confraternidad entre soldados y oficiales, como augurando que ante la muerte todos iban a ser iguales. ${ }^{35} \mathrm{Y}$ El Puerto se preocupaba por aquellos reclutas, muchos de ellos analfabetos, que sin haber visto nunca un fusil, debían marchar a una contienda que se sabía ya perdida de antemano.

En este año de 1898 que nos ocupa, de los 137 mozos alistados 45 fueron declarados exentos ante el correspondiente tribunal médico. Como causas mas frecuentes: insuficiencia en la talla, cataratas, lesiones en la columna o en las articulaciones, dificultad para respirar, dolor en el pecho... De la lectura de las correspondientes actas parece desprenderse una cierta permisividad de las citadas autoridades médicas, aunque por razones obvias resulta imposible saber si era debida a razones puramente humanitarias o económicamente interesadas.

Actitud que parece fue compartida en cierto modo por el propio Ayuntamiento, ya que de los 92 mozos restantes sólo 35 embarcarían rumbo a ultramar, frente a los otros 57 que no llegarían jamás a presentarse. ${ }^{36}$ Aunque de este último grupo se desconoce por ahora el porcentaje de prófugos y de "redimidos".

En cuanto a los primeros, no se puede olvidar que el darse a la fuga era el medio más radical de eludir la tan problemática llamada a filas, y que fue el elegido por una significativa parte de la población española. ${ }^{37}$ Respecto a los segundos, su servicio a la patria les quedaba legalmente conmutado por la entrega de una sustanciosa cantidad a las arcas estatales, las cuales, al estar prácticamente exhaustas, potenciaban semejante medida. Situación toda ella profundamente injusta que comenzaba a plantear la necesidad de un servicio militar obligatorio, similar al prestado en otras partes de Europa. No en vano el Comité Nacional del Partido Socialista había remitido el siguiente comunicado:

"Trabajadores, es preciso que no nos dispongamos a consentir que se envíe a la manigua, solamente a los hijos de los que nada tienen, de los que diariamente son

35 Baraja: La Guerra de Independencia..., págs. 52-53.

36 AMPSM, actas de cabildo. Reclutamiento y reemplazo de mozos para la Guerra de Cuba, El Puerto, 6-10, 14 y 26 de marzo de 1898, fols. 55-89.

37 Serrano, Carlos: "Prófugos y desertores en la Guerra de Cuba". Estudios de Historia Social, Madrid, 1982, núms. 22-23, págs. 253-278. 


\section{M. ${ }^{\text {a }}$ DEL CARMEN BORREGO PLÁ}

despojados de la parte principal del fruto de su trabajo, por quienes, hablando a todas horas de patriotismo, ni empuñan el fusil ni mandan a sus hijos a los campos de Cuba". ${ }^{38}$

No obstante El Puerto continuaba siendo un marco idóneo para el paso de fuerzas y más fuerzas procedentes de Andalucía, Extremadura, parte de Castilla..., camino de la inmensa boca gaditana. La situación llegó a tales dimensiones, que en julio el Ayuntamiento libraba 3.000 pesetas de su capítulo reservado a "gastos imprevistos", para alimentar aquella marea humana. ${ }^{39}$ Pero ninguno de estos esfuerzos iba a servir de nada. Desde el desastre de Montojo en Cavite - Filipinas—, se presagiaba el fin de nuestra armada.

La noticia cayó en toda la Península como un auténtico revulsivo, incluida por supuesto la localidad portuense: “¡España no ha sido vencida ni lo será: el favor de Dios, la justicia que le asiste y el valor de sus hijos la ayudarán...!". Por otra parte, se arremetía contra aquellos españoles —sin citar nombres- que a pesar de sucesos tan adversos, seguían comerciando veladamente con la Unión:

"Contra la nación infame que nos deshonra, calumnia y pretende robarnos... Quizás hagamos fruncir el ceño a algunos católicos patricios que continúan embarcando sus productos a los mercados de la Unión americana en bandera inglesa, para seguridad de su honrado negocio.. Jamás ningún español de verdad se prestaría a este tipo de juego... Y si lo hubiere, no merece serlo, llámese como se llame". ${ }^{40}$

Mientras tanto la coyuntura en Cuba era muy negativa, para una tropa española que se encontraba mal instruida, mal vestida y en un escenario de operaciones muy difícil de abordar, dadas las condiciones físicas, tan diferentes a las peninsulares, que presentaba. Agotamiento y fiebre resultaban monedas corrientes, pero también lo era el hambre. Porque los pequeños comerciantes cubanos se negaban a seguir sirviendo los suministros al ejército mientras éste no pagase sus deudas, con lo que la alimentación dejaba mucho que desear, fundamentalmente en lo relativo al abastecimiento de carne. El corresponsal en Manzanillo de El Imparcial hacía tiempo que lo había denunciado: "No hay nada de lo mas indispensable y las columnas

38 Baraja: La Guerra de Independencia..., pág.52. Hernández y Mancebo: Higiene y sociedad..., págs. 370-372.

39 AMPSM, acta de cabildo, 1 de julio de 1898, fol. 33.

40 "Ligereza Inconcebible" y "Los yanquees de acá". La Región, 14 y 28 de mayo de 1898. 
están en una situación delicadísima: tienen la mitad de la gente en los hospitales y la otra mitad sin comer". ${ }^{41}$

Y los días fueron transcurriendo sin apenas cambios, con la lenta angustia de los que se saben condenados. Aunque no faltaban las arengas de algunos conservadores radicales que, como los de El Puerto, llegaban a empecinarse:

"España prefiere como Hernán Cortés, quemar sus naves y quemar con ellas a todos esos infames ... que la han conducido a tal extremo... - Los cuales - desean la paz para obtener por el ardid diplomático lo que son imposibles de arrancar por la fuerza y —así- que el león español arrastre su melena por la inmunda zahurda del cerdo". ${ }^{42}$

Pero cuando el temido y definitivo golpe se materializó, cuando lo que quedaba de la flota española al mando el almirante Cervera, caía durante el mes de julio ante los norteamericanos en la bahía de Santiago de Cuba, el impacto entre los españoles resultó memorable. Y El Baluarte sevillano llegaría a ironizar: "A la orilla de un arroyo/ me puse a considerar/ aquí cabe nuestra escuadra/ y hasta puede navegar/" ${ }^{43}$ El 12 de agosto se firmaba el cese de hostilidades de una guerra, que desde 1895 le había costado a España unos 1.500 millones de pesetas y 64.000 bajas. ${ }^{44}$

\section{Entre la solidaridad y el criticismo}

Y en semejante coyuntura, cuando las dos Españas, la liberal y la conservadora, se mantenían enfrascadas en una durísima diatriba política, lamentando lo que ya no tenía remedio, toda la provincia de Cádiz, al igual que había ocurrido antes con la guerra de Africa, iba a dedicarse al permanente consuelo de tanta aflicción humana. Cuando los "caídos en la manigua", victimas de la debilidad y la fiebre — que no tanto por herida de bala según hemos visto-, desembarcaban en el puerto gaditano, dos humildes "casetas" los recibían. La primera, destinada a los respectivos reconocimientos médicos. La segunda, convertida en hospital temporal para aquellos que lo necesitasen. Pero la capital provincial no daba abasto: camillas, enfermos, familiares, llantos... Eran las llagas de una contienda tan injusta

41 Hernández y Mancebo: Higiene y sociedad..., págs.365-367.

42 "La Ley de la Expiación". La Región, 11 de julio de 1898.

43 Sevilla: La Guerra de Cuba y la memoria..., págs.128-129.

44 Navarro: La Independencia..., pág. 381 
como desastrosa. El Casino Gaditano -en colaboración con Los Hermanos de San Juan de Dios-, así como el Cuartel de San Fernando se volcaron con este trozo de España doliente..$^{45}$ Pero aún no era bastante.

Por ello se escogía de nuevo El Puerto como solución. Ya en julio la Comisión de Beneficencia Provincial había solicitado información sobre los lugares más adecuados para el cuidado de los enfermos. Y el consistorio había respondido que para tal menester podía servir el otrora edificio de La Aurora, antigua institución portuense de gran prestigio, mezcla de cofradía, centro de estudios y biblioteca, la cual se encontraba situada colateralmente a la Iglesia Prioral. ${ }^{46}$ Aunque su acondicionamiento supondría un costo de 5.000 pesetas y aproximadamente setenta días de trabajo. ${ }^{47}$

Sin embargo el rápido desenlace de la guerra hizo imposible la materialización de dicho proyecto y ante la advertencia de que en el mes de septiembre llegarían a Cádiz 1.500 enfermos, el citado consistorio portuense se vio obligado a buscar alguna solución alternativa. Esta vendría dada por el ex convento de Santo Domingo, con capacidad para cien camas, así como por el pabellón de alienados del Penal de La Victoria, en donde podrían instalarse doscientas más. El resto debía repartirse entre la capital de la provincia y otros pueblos de la comarca, fundamentalmente Jerez de la Frontera. La magnitud de todo el fenómeno podría medirse por el hecho de que Cádiz se viera obligada a levantar no sólo un hospital de sangre y dos casas de socorro nuevas, sino incluso a ampliar la capacidad de su cementerio ${ }^{48}$ Por su parte el sentir general de la población portuense al respecto, quedaba manifiestamente claro en un artículo que bajo el expresivo título de "Despojos", aparecía publicado por aquellas fechas:

45 Millán Chivite, José Luis: "EL Noventaiocho en Cádiz: el ocaso de una gran ciudad portuaria y comercial" en Cádiz en el siglo XX, vol. IV de Historia de Cádiz (coord. Manuel Bustos), Madrid, 1993, págs. 25-27 y "Cádiz y la Crisis de 1898: Recuerdo de la derrota y la Tragedia". Gades, n. ${ }^{\circ}$ 20, Cádiz, 1992, págs. 317-326. "Los Reembarcados". La Revista, 6 de octubre de 1898. Como muestra del tratamiento dado a los repatriados por la prensa de Madrid, puede consultarse el trabajo de Rafael Núñez Florencio: "Los otros españoles que fueron a Cuba: el drama de los repatriados" en $L a$ Nación..., págs. 597-621.

46 Sancho de Sopranis, Hipólito: Un Centro Cultural del siglo XVIII. La Cofradía y Escuelas Pías de Nuestra Señora del Rosario de la Aurora. El Puerto de Santa María, 1993.

47 AMPSM, legajo 1282, Guerra 1898, n. ${ }^{\circ}$ 5. Comisión de Beneficencia al alcalde de El Puerto, Cádiz, 14 de julio de 1898 y el alcalde de El Puerto a la Comisión de Beneficencia, El Puerto, 23 de julio de 1898 .

48 Ibídem. El gobernador de Cádiz al alcalde de El Puerto, Cádiz, 5 de octubre de 1898 y el alcalde de El Puerto al gobernador de Cádiz, El Puerto, 6, 14 y 19 de octubre de 1898. Cano, Las Defensas de la Bahía, págs. 133-134. 
"Al descender del tren — los repatriados — parecían despojos que se alzaban de sus tumbas para arrojar sobre nuestras frentes la maldición que por enormes culpas merecemos...jPobres despojos de la guerra y que mal os paga esta España por la que habéis perdido la salud!" ${ }^{49}$

De ahí que los acogidos en dicha ciudad recibieran no sólo el apoyo médico, sino también moral, "porque necesitan mucho cariño, cuidados y auxilio espiritual". A todos ellos se les proporcionarían "buenas camas y colchones, no faltándoles en su alimentación caldo, leche y huevos". A destacar, las limosnas del vecindario, que canalizadas a través de la Cruz Roja, servirían para todo lo expuesto, así como para financiar los entierros de los fallecidos o la ropa de aquellos que, ya restablecidos, regresaban a sus hogares — vino, tabaco, calcetines, pañuelos, chalecos de bayona...-. ${ }^{50}$

A pesar de todo, no eran éstas las únicas cuestiones que martilleaban a nuestra opinión pública. Existían algunas otras que también eran compartidas por el resto del territorio nacional. Así, por ejemplo, se tenía una gran preocupación por las insuficientes garantías higiénicas ofrecidas a la tropa recién regresada a España. Como contraste se citaba a la desembarcada por Barcelona, que ingresaba inmediatamente en el Instituto de Higiene. Allí, tanto los enfermos como los que no lo estaban, recibían todo tipo de atenciones, desinfectándoseles las ropas y permaneciendo en dicho Centro unos días, hasta estar plenamente curados o, en su caso, restablecidos, después de un necesario intervalo de descanso. ${ }^{51}$

De dicha manera, al regresar a sus hogares se tenía la plena seguridad de que no iban a propiciar —otra vez el miedo a la epidemia - un contagio de fiebre amarilla. Opinión ésta que no resultaba nada gratuita, ya que era compartida por muchos profesionales de la medicina como el doctor Tejeiro, rector de la Universidad de Santiago, quién afirmaba lo siguiente:

"el peligro es muy grande y hay que impedir a toda costa que los enfermos, antes de su completa curación, se desparramen por el país". ${ }_{52}$

Incluso muy en relación con todos estos razonamientos, se había llegado a presentar en Madrid un proyecto —el cual parece no prosperó-

49 "Despojos". La Revista, 23 de noviembre de 1898.

50 "Por los Repatriados". Ibídem, 21 de noviembre y 2 de diciembre de 1898.

51 "Los Reembarcados" y "La Salud Pública". Ibídem, 6 de octubre de 1898.

52 Hernández y Mancebo: Higiene y sociedad..., págs. 382-383. 
proclive a que todos los soldados y civiles provenientes de Cuba pasaran una "cuarentena" en aquellos lugares de las Islas Canarias previamente seleccionados para tal fin. Se argumentaba que al gozar estas últimas de unas condiciones físicas muy similares a las cubanas, se ayudaría a una mejor aclimatación de los recién llegados, conjurándose asimismo cualquier peligro epidemiológico para la Península. ${ }^{53}$

Aunque a este respecto ya comenzaban a alzarse algunas voces - la del doctor González del Valle por ejemplo-, advirtiendo que el mayor problema no radicaba tanto en la tan citada y temida fiebre amarilla — dado su difícil arraigo en un territorio con las características del español—, como en

"esas masas de tuberculosos que nos está enviando Cuba desde el comienzo de la campaña y que originan en nuestros ciudadanos grandes focos de infección, que andando el tiempo, han de producir mas víctimas entre los que no han ido a la guerra, que la guerra misma". ${ }^{44}$

Pero la indignación mayor de los portuenses se centraba en todo lo relativo a las pensiones de guerra. Gente inútil, viudas y huérfanos de sus propios vecinos, que no alcanzaban a obtener las compensaciones económicas prometidas y a las cuales tenían pleno derecho. Ya en Sevilla el citado Baluarte había llegado a escribir algún tiempo atrás: "Los soldaditos de $\mathrm{Cuba/hace} \mathrm{un} \mathrm{año} \mathrm{que} \mathrm{no} \mathrm{cobran/} \mathrm{en} \mathrm{cambio} \mathrm{los} \mathrm{arzobispos/} \mathrm{alhajas} \mathrm{y} \mathrm{oro}$ les sobran/". ${ }^{55}$ El Estado estaba pues en franca bancarrota y las bocas pedían pan. Nuestro vecindario en cuestión hizo lo que pudo: mantas, ropas, presión ante Cádiz a través de la propia prensa... Se llegó incluso a solicitar que el dinero que se tenía recaudado para la Suscripción Nacional, se quedara en El Puerto como socorro de estos hijos necesitados, porque "¿Qué hacen ahora - las autoridades - que no acuden en auxilio de los que cumplieron su voluntad, de los que fueron al sacrificio, porque así se lo pedía España?". ${ }^{6}$

Mientras tanto se iniciaban los preparativos de lo que luego sería conocida como la Paz de París, pero el refrendo internacional de la pérdida cubana poco importaba ya. La firma de la misma en diciembre del agónico 98, sólo sería recogida en escuetas notas de prensa, sin ningún comentario al respecto. A destacar, el reiterativo tratamiento dado a los restos de

53 Véase nota 51.

54 Ibídem.

55 Sevilla: La Guerra de Cuba y la memoria..., pág. 142.

56 "Por los Repatriados". La Revista, 1 de octubre de 1898. 
Colón - "el último repatriado"-, que iban a ser trasladados desde la catedral cubana a la "Madre Patria". ${ }^{7}$

Sin embargo no todos creían acertado olvidarse del pasado dejado atrás, al otro lado del Atlántico. En este sentido muy a tenerse en cuenta fue el enjundioso artículo - "Nuestro Porvenir Colonial"- que en noviembre y bajo la firma de Alfau Baralt, publicaba la tantas veces nombrada Revista Portuense. En el mismo se abogaba en favor de no cortar las pocas amarras aún existentes con aquellas nuevas naciones americanas -incluida por supuesto Cuba-, las cuales conformaran antiguamente el imperio español. Se aceptaba que el papel de España en el Nuevo Continente había terminado, pero no por ello quedaba sin reconocimiento - a pesar de sus defectos-, la profunda huella dejada.

"Porque el fin de toda colonización es proporcionar o procurar un campo de expansión de las fuerzas vitales y productivas de los pueblos. Y esto se ha hecho: se ha llevado vida, costumbres, actividad y soberanía..."

No obstante no dolían prendas para denunciar el tremendo error cometido al atrincherarse el gobierno español en posiciones políticas nada aperturistas: "Sin embargo el signo de soberanía ha sido el mas conflictivo, porque ha debido de modificarse, como por ejemplo Inglaterra, creando una autonomía especial como en Canadá o un imperio como en la India...". Y la consideración final, de clara raíz premonitoria:

"Nuestro porvenir está allí donde hemos dejado jalones de nuestra raza, de nuestra sangre, de nuestro genio nacional: La Unión Iberoamericana, pero que no sea simplemente una institución romántica, idealista. Cohesión directa y solidaridad entre todos los pueblos, defendiéndose de todo tipo de agresión posible. Porque el duelo a muerte está planteado desde los días de Monroe". ${ }^{88}$

Pero El Puerto tampoco era ajeno al profundo y combativo sentido crítico - a veces teñido de un cierto desencanto-, que estaba extendiéndose a lo largo y ancho de España, pues como ya había sentenciado $E l$ Progreso Sevillano: "no se trataba de morir por la patria, sino de vivir para

57 Como estudio de conjunto sobre los posicionamientos e impacto que a nivel internacional se produjeron con motivo de la pérdida de Cuba, puede consultarse La Nación Soñada..., cap. VII, pags. 695-818. "Los Restos de Colón", "Colón Empaquetado" y "El Gran Repatriado". La Revista, 2 y 27 de octubre de 1898 y 2 de enero de 1899.

58 "Nuestro Porvenir Colonial", escrito por Antonio Alfau Baralt en el Puerto, el 26 de noviembre de 1898 y publicado por La Revista, 27 de noviembre de 1898. 
ella, olvidando su caduco significado del honor hasta entonces vigente". ${ }^{59}$ Y en nuestra localidad en cuestión, dicho espíritu regeneracionista lo estaba abarcando todo: la política, la milicia, la economía... La patria tenía que aprender de sus errores y se necesitaban hombres nuevos que timonearan el también nuevo rumbo que debía iniciarse.

Obviamente los portuenses exigían responsabilidades por lo sucedido, pero ahora la crítica más dura no se centraba tanto en la acción de gobierno ejercida en Cuba, como en la desorganización de la posterior contienda. Unánimemente se calificaban de "vergonzosas" las condiciones en las que habían tenido que combatir los soldados y se reconocía que su mayor enemigo había estado en "la manigua", para la que ni oficialidad ni tropa habían sido preparadas.

$\mathrm{Y}$ mientras todas estas cuestiones iban corriendo de boca en boca, cada vez iba ganando más importancia el papel de la marina, que — siempre según los citados portuenses - nunca había gozado de la atención y aprecio que merecía. Por ello un clamor generalizado solicitaba su aumento y reconversión, recordando en muchos aspectos la filosofía que un siglo atrás desplegara el marqués de La Ensenada, tan vinculado con esta tierra en donde vivió algunos años. Toda la bahía y el traspaís gaditano recordaban con auténtica añoranza su labor como máximo responsable de la marina española, en la que tan presente había estado la construcción naval y la creación del arsenal y carenero de La Carraca, sito en el vecino San Fernando. No podía olvidarse como desde siempre los portuenses habían vivido pendientes de la mar; y por razones tanto defensivas como económicas, se hallaban interesados en conseguir la mejor marina posible, así como la potenciación de los correspondientes astilleros. Las élites locales, porque sus productos necesitaban transportes rápidos y fletes baratos; la autoridad militar, porque así se lo pedía la defensa de una zona geoestratégica tan importante como la gaditana; y por último el pueblo llano, porque mayoritariamente vivía de la pesca o del trabajo - como mano de obraen los pequeños varaderos locales e incluso, a veces, en los dos grandes centros gaditanos por excelencia: el astillero de la Compañía Transatlántica o el de Vea-Murguía. ${ }^{60}$

59 Sevilla: La Guerra de Cuba y la memoria..., pág. 94.

60 Para todo lo referente a la filosofía política del marqués de La Ensenada y a sus relaciones con El Puerto y Cádiz, resulta de interés el estudio de Borrego Plá: "Los universos reformistas de Ensenada: una visión anónima de los hombres de su tiempo". Temas Americanistas, n. ${ }^{\circ} 14$ (en prensa). Millán: El Noventaiocho en Cádiz..., pág. 33. Cano: Las Defensas de la Bahía..., pág. 135. 
Y en tal sentido se veía conveniente la unión del Ministerio de Guerra con el de Marina, para que existiera una mayor y mejor coordinación, así como la creación de un cuerpo de artilleros de armada, y otro dos de pilotos y maquinistas, "distinguidísimos por su utilidad". E igualmente considerábase deseable, el que los ingenieros navales pudieran ampliar estudios en las respectivas academias militares. Aunque el mayor énfasis estaba puesto en el nuevo papel que debía desempeñar la armada, no sólo como defensa, sino también como apoyo a los intereses internacionales y comerciales de España. Por ello se le debía de equipar con los mejores adelantos técnicos y el personal más cualificado. Estaba claro que el reciente ejemplo de la marina norteamericana no se había echado en saco roto. ${ }^{61}$

Pero junto a todo lo expuesto, se asistía también a un efervescente afán desarrollista que se reflejaba en todo tipo de tribunas, especialmente las periodísticas, intentando potenciar el exhausto nervio económico de la zona. ${ }^{62}$ Desde las mismas se abordarían los perfiles estructurales mas modernos — cultivo de la remolacha—, pero también la incentivación delos mas tradicionales, fundamentalmente el consabido vino o la pesca.

Respecto a la producción vinícola, se propugnaban soluciones tan acertadas y novedosas como el injerto con vides americanas para frenar la plaga de filoxera o la búsqueda de nuevos mercados, dado que uno muy significativo, el cubano, acababa de perderse por razones obvias. Igualmente se aconsejaba una mejor calidad en los vinos y un abaratamiento en sus costes; cuestión ésta que por parte del gobierno debía implicar la supresión de aquellos impuestos especiales con los que se gravaban todos los caldos que salían desde al puerto de Cádiz y que habían ayudado a financiar la terrible guerra. ${ }^{63}$ En cuanto a la pesca, se predicaban varias opciones que iban desde significativas mejoras laborales para las tripulaciones, hasta la modernización de la flota artesanal, pasando por la creación de "laboratorios hidrológicos" — viveros- o la repoblación de especies en el Guadalete, por citar sólo algunos ejemplos. ${ }^{64}$

El Puerto de Santa María iniciaba pues, esperanzado, una nueva andadura histórica que lo iba a llevar por caminos crispados y terriblebre de 1898 .

61 "De Interés" y "Lo que dicen los Repatriados". La Revista, 27 de agosto y 22 de septiem-

62 Para un estudio comparativo del mismo fenómeno en Sevilla, resulta muy útil la obra de

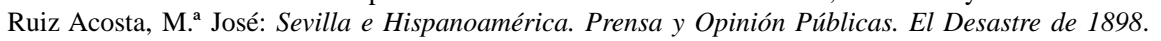
Sevilla, 1996.

63 Borrego: "El comercio del vino...”, págs. 467-469.

64 Borrego: "Prensa y Pesca...", págs. 109-119. 
mente problemáticos; pero todo ello aún se desconocía. Por aquel entonces destacaba, como colofón a todo lo expuesto, un editorial de sugestivo título - "Peligros para el Devenir"-, aparecido en la prensa local el 17 de septiembre y en el cual, dentro de un profundo afán revisionista, realmente se profetizaba la sesgada visión - a veces víctima de manipulaciones interesadas-, que sobre el Desastre del 98 iban a propiciar las generaciones venideras:

"En España no se enseña historia... Nos hemos acostumbrado a considerar espada y lanza, fusil y cañón como únicos causantes de nuestro poderío o de nuestra crítica. Nos han embebecido con cuatro pinceladas de relumbrón... La historia de los pueblos es algo mas que los hechos gloriosos o desgraciados. Es necesario poner de manifiesto su estado social, su carácter, su instinto, la construcción de la familia, sus aptitudes administrativas. Cuando nuestros descendientes narren la hecatombe actual y expliquen el entusiasmo público de los puertorriqueños por los yankees, el contenido aún del elemento cubano que no está por la insurrección y el de gran parte del comercio de Manila, lo achacarán a causas muy ajenas a las verdaderas y saldrán héroes y traidores de los que hoy no tenemos ni la mas remota idea". ${ }^{65}$

65 “Peligros para el Devenir”. La Revista, 17 de septiembre de 1898. 